\title{
Jornalismo de dados e cobertura política: uma análise da atuação do DeltaFolha nas eleições municipais de $2020^{1}$
}

Vitória de Figueiredo Brandão Souza

Pontifícia Universidade Católica do Rio de Janeiro - PUC-Rio

Departamento de Comunicação Social - Bacharelado em Jornalismo

\section{Resumo}

Esse trabalho é uma proposta de análise da cobertura das eleições municipais de 2020 por parte do DeltaFolha, a seção de jornalismo de dados do jornal Folha de S. Paulo. Para tanto, foi realizado um estudo com base em dezoito reportagens levantadas durante o período eleitoral. A partir desses textos, foram utilizados critérios de noticiabilidade definidos por Nelson Traquina para a condução de estudos sobre a inclinação dessas matérias.

Palavras-chave: Jornalismo de dados; Noticiabilidade; Jornalismo; Infográficos; Internet.

\section{Introdução}

O presente trabalho se propõe a conduzir um estudo acerca da relação entre critérios de noticiabilidade e matérias investigativas produzidas pela seção DeltaFolha da Folha de S. Paulo. As análises realizadas buscam a associação entre um olhar crítico e uma visão analítica frente à forma como esse veículo busca estruturar sua cobertura política com base no jornalismo investigativo de dados.

Nessa pesquisa, entendemos o jornalismo investigativo como uma modalidade singular, uma vez que se constitui como uma prática que envolve uma análise mais profunda e extensa sobre determinada pauta (AGUIAR, 2006). Nesse contexto, a seção DeltaFolha do site do jornal Folha de S. Paulo se destaca no meio jornalístico nacional por apresentar uma proposta de agrupamento de matérias onde editores utilizam como base para a construção de um storytelling, o uso de informações numéricas. O storytelling, por sua vez, pode ser definido como a atribuição de uma narrativa, realizada por parte de um profissional de comunicação, a um conjunto de dados.

\footnotetext{
${ }^{1}$ Artigo derivado de monografia de graduação em Jornalismo, orientada pela professora Carmem Petit e entregue em dezembro de 2020.
} 
Em uma era em que, cada vez mais, a desinformação exerce influência sobre a sociedade, o papel de um jornalismo crítico se torna essencial. Dessa forma, o jornalismo de dados e o storytelling convergem para proporcionar uma abordagem única à reportagem. De acordo com Domingos (2008), o storytelling tem como objetivo garantir uma função de persuasão a uma narrativa, visto que informa, mas também forma princípios frente ao público consumidor contribuindo, deste modo, para a formação da opinião pública.

O jornalismo investigativo se articula em confluência com o conceito de storytelling. Waisbord (2000) sublinha como a modalidade investigativa trabalha com apuração extensa de informações, ao invés da simples reprodução de conteúdo compartilhado por fontes informativas para as redações de jornais. O trabalho do jornalismo de dados opera de modo similar, buscando pautas ocultas em dados coletados. Portanto, percebe-se como essas duas modalidades coexistem de maneira simbiótica, estando profundamente associadas uma à outra.

Apresentamos ainda uma observação alicerçada nos critérios de noticiabilidade descritos por Nelson Traquina (2008). Pioneiro na categorização de reportagens, ele apresenta em sua descrição teórica do jornalismo uma série de aspectos-chave que norteiam esta pesquisa, sendo o mais relevante desses a introdução dos critérios anteriormente citados como uma forma de analisar reportagens e matérias a partir da identificação de inclinações discursivas.

O modelo apresentado pela Folha se espelha em exemplos de sucesso presentes em mercados internacionais, como o site The Upshot, mantido pelo periódico norte-americano The New York Times desde 2014, que combina "jornalismo analítico com palavras e gráficos". Outro exemplo, dessa vez no continente europeu, é o Datablog +, seção online do britânico The Guardian. A decisão da Folha em apostar nesta iniciativa está alinhada não apenas com os grandes jornais do eixo Europa-Estados Unidos, mas também com publicações na periferia do capitalismo como o Thmey Thmey News, do Camboja, e o Premium Times, da Nigéria.

Para a condução do presente trabalho, foram observadas as matérias da editoria de política da seção DeltaFolha do site da Folha de S. Paulo. As reportagens levantadas foram publicadas entre os meses de setembro e novembro de 2020, a partir da data de início da propaganda eleitoral.

Embora o norte teórico deste trabalho sejam os critérios de noticiabilidade descritos por Nelson Traquina, também recorremos ao pensamento de Michael Schudson, Stuart Hall e Lia Seixas. Metodologicamente, realizamos ainda entrevistas com jornalistas responsáveis pela elaboração das pautas e reportagens veiculadas no DeltaFolha, de forma a compreender os processos 
internos que levaram à criação da seção, assim como, também, explicitar o grau de relevância do DeltaFolha na versão digital da Folha de S. Paulo.

Lidar com dados e associá-los com a reportagem é imperativo na prática jornalística moderna. Em um cenário onde dados estão mais disponíveis do que nunca, é papel do jornalista analisar, tratar e disponibilizá-los para o público de uma maneira compreensiva.

A partir dessas associações, este trabalho busca destacar a relação entre os critérios de noticiabilidade e o direcionamento apresentado pelas reportagens selecionadas, a fim de compreender como o uso dos dados contribui para um storytelling que, em última instância, influencia o pensamento crítico do público consumidor de informação. Desta forma, tecendo um olhar compreensivo acerca das modalidades de jornalismo anteriormente citadas.

\section{Jornalismo de dados: Definições e relevância política}

O jornalismo tem como tradição a sua própria reinvenção. Essa afirmação se comprova por meio de um olhar objetivo acerca da prática ao longo dos séculos. Desde o surgimento dos periódicos impressos no século XV, passando pelo surgimento do rádio e da televisão, no fim do século XIX e início do século $X X$, até a introdução do digital na virada do milênio, é possível notar como a comunicação e, dentro dela, o jornalismo, se transforma para se adaptar às ferramentas e arranjos empresariais e sociais que são difundidos em determinado recorte temporal.

O presente trabalho, portanto, se propõe a delinear a relevância do jornalismo de dados como modalidade de produção de reportagem em um cenário de indissociação do meio digital com a prática jornalística. Esta simbiose pode ser constatada a partir da consolidação das redes sociais, do surgimento de novas plataformas para veiculação de informações e do incremento do consumo de conteúdo a partir de websites e aplicativos (DUTTA; GANGOPADHYAY,2019). A partir desses conceitos, destaca-se, em específico, a utilização do jornalismo de dados para a cobertura política, assim como sua crescente associação com o jornalismo investigativo.

De início, anteriormente à compreensão das nuances inerentes a ascensão do jornalismo de dados no contexto político contemporâneo, cabe salientar o papel do jornalismo em si na manutenção das instituições democráticas (TRAQUINA, 2008). A liberdade de imprensa é um componente chave na veiculação de uma pluralidade de discursos que, por sua vez, asseguram a continuidade de regimes democráticos, como sublinhado por Sousa (2008). 
Tal dinâmica se comprova ao direcionarmos um olhar histórico para o impacto da ação da imprensa em diversos contextos políticos da história brasileira, sob a perspectiva da comunidade acadêmica. O impeachment da ex-presidente Dilma Rousseff, em 2016, se apresenta como um campo fértil para essa análise. Feres Jr. e Sassara (2016, p. 183) descrevem o afastamento da então chefe de Estado como uma confluência de inúmeros fatores, "todavia é difícil imaginar como todos esses elementos entraram em sinergia sem a ativa colaboração da mídia". Na mesma perspectiva de pensamento, Nunes e Melo (2017) argumentam que o alinhamento entre a narrativa midiática e o posicionamento do Congresso exerceram papel fundamental no resultado do processo de impedimento.

Consequentemente, delimita-se, para fins desta análise, uma paisagem no campo da comunicação caracterizada por: ênfase no digital, maleabilidade do jornalismo e papel central do mesmo frente a opinião pública. Dessa forma, nota-se como o uso sistematizado de dados, prática impulsionada pela consolidação do meio virtual na condução de rotinas individuais, se revela como um campo fértil para mais uma reinvenção do jornalismo.

A crescente implementação do uso de dados integra as estratégias recentes de grandes veículos a partir da disrupção de seus modelos de negócios. Howard (2014) destaca que novos modelos empresariais estão emergindo e os dados são o aspecto central na articulação de estratégias que asseguram uma balança comercial positiva. Esses dados, por sua vez, são produto de um público consumidor anteriormente percebido como essencialmente passivo. Uma sociedade mais conectada do que nunca, onde ações podem ser quantificadas, se mostra um campo fértil para a apropriação dessas informações, em seus mais diferentes contextos, para a investigação e produção de pautas.

A prática jornalística, agora, perpassa a construção de narrativas a partir da coleta e análise de quantidades vastas de informações metrificadas em nossas vidas cada vez mais digitais. Powell (2016) destaca que a quantidade disponível de dados também vem se expandindo à medida que governos tornam informações públicas. No recorte temporal referente ao século XXI, a pressão por transparência e prestação de contas junto ao público por parte de órgãos governamentais também contribui para um incremento na quantidade de informações disponíveis.

Portanto, o papel do jornalismo passa a se traduzir, também, em uma atividade interpretativa, resgatando os dados disponíveis e conferindo a eles uma narrativa de forma a garantir sua compreensão frente ao público. 
Ao iniciar uma discussão sobre a construção de narrativas no contexto do jornalismo, faz-se necessário sublinhar o conceito de storytelling e suas definições.

Storytelling é a descrição vívida de ideias, crenças, experiências pessoas e lições de vida através de histórias ou narrativas que evoquem poderosas emoções e introspecção. O storytelling tem vantagens sobre técnicas de comunicação frequentemente utilizadas em organizações, seja correio eletrônico, relatórios ou discursos formais. Primeiramente, permite a articulação de aspectos emocionais, assim como conteúdo factual, permitindo expressão de conhecimento tácito (o que sempre é difícil de transmitir). (SERRET, 2008, p. 1)

A natureza crua de informações quantitativas só passa a ser transformada em uma pauta propriamente dita após a atuação crítica e conferência de um valor noticioso por parte do jornalista. Esse tratamento, por sua vez, não é um processo intuitivo. Por esse motivo, Berret e Philips (2016) destacam a importância da inclusão do jornalismo de dados na formação universitária, de maneira a treinar de maneira mais objetiva a próxima geração de profissionais que virão a integrar a força de trabalho.

\section{Critérios de noticiabilidade e o novo ambiente digital}

Valores-notícia são o alicerce da prática jornalística, sendo definidos como "todo e qualquer fator potencialmente capaz de agir no processo da produção da notícia" (SILVA, 2005, p. 96). Ou seja, são eles que conferem a um fato seu potencial noticioso. O destaque para a importância dos valores-notícia se faz imperativo uma vez que nem todo fato é notícia, como destacam Alves e Seixas (2017):

Em um produto dito jornalístico, nem tudo é jornalismo. Portanto, nem tudo é notícia. Consequentemente, nem tudo tem valor-notícia. Ao mesmo tempo, exceto horóscopo, cartoon e publicidade, por exemplo, a materialidade é, geralmente, influenciada por algum critério de noticiabilidade, seja da ordem do interesse do público ou da organização. (ALVES; SEIXAS, 2017, p. 158)

A origem dos critérios de noticiabilidade pode ser traçada em análise de Galtung e Ruge, de 1965, quando, os autores observam a estrutura do noticiário em quatro jornais estrangeiros sobre as crises no Congo, Cuba e Chipre, e propõem doze critérios de sistematização da reportagem, divididos em:

F1: Frequência; F2: Amplitude; F2.1: Intensidade absoluta; F2.2: Aumento de intensidade; F3: Inequivocidade; F4: Significância; F4.1: Proximidade cultural; F4.2: Relevância; F5: Consonância; F5.1: Predicabilidade; F5.2: Exigência; F6: Imprevisibilidade; F6.1: Impredicabilidade; F6.2: Escassez; F7: Continuidade; F8: Composição; F9: Referência a nações de elite; F10: Referência a pessoas de elite; F11: 
Referência a pessoas; F12: Referência a algo negativo (GALTUNG; RUGE, 1993, p. 71).

Embora o pioneirismo de Galtung e Ruge se traduza em uma proposta revolucionária para o campo da comunicação, Seixas (2018) argumenta que a chamada equação de doze fatores não funcionou como fenômeno social, o foco dos estudos da noticiabilidade. Esse caráter exacerbadamente matemático do modelo de Galtung e Ruge também é criticado por Silva (2010), que destaca como

[...] o modo como os autores apresentam sua perspectiva, amparados em hipóteses que seguem relações matemáticas (o que revela uma ancoragem no modelo positivista da ciência), enrijece as categorias de valores-notícia e coloca o estudo em uma posição passível de revisões críticas a partir de abordagens guiadas pela perspectiva culturalista. (SILVA, 2010, p. 174)

Porém, inegavelmente, a pesquisa realizada pela dupla de noruegueses deu início a uma série de análises posteriores aprofundadas acerca desse campo de estudo do jornalismo. Nas décadas seguintes, Golding e Elliott (1979) apresentaram uma proposta de valores-notícia delineados a partir dos conceitos de audiência, acessibilidade (ou seja, importância e facilidade de cobertura) e adequação (às restrições organizacionais de um veículo).

[...] Grande parte dos estudos que se dedicaram a categorizar valores noticiosos teve finalidade principal de sistematizar critérios de reconhecimento e classificação dos eventos. Carecem da construção de um corpo de princípios integrados e articulados que dariam aos estudos a possibilidade de se tornarem teorias. (FRANCISCATO, 2014, p. 87)

Os critérios de Traquina, escolhidos para a realização do presente trabalho, se constroem a partir de contribuições anteriores de diferentes autores. Traquina, em sua obra, elabora uma sistematização didática a partir da coleção de uma série de propostas de critérios de noticiabilidade que, até então, se encontravam academicamente dispersas. Para o autor, o esquema geral das notícias se torna previsível por conta da forma como os critérios são compartilhados pela comunidade jornalística. As notícias são, então, "o resultado de um processo de produção, definido como a percepção, seleção e transformação de uma matéria-prima (os acontecimentos) num produto (as notícias)" (TRAQUINA, 1993, p. 169).

Alves (2018) destaca que as definições de Traquina partem de uma organização de critérios a partir de valores de seleção, subdivididos em substantivos e contextuais, e valores de construção.

O valores-notícia de selecão estão divididos em dois sub-grupos: a) os critérios substantivos que dizem respeito à avaliacão direta do acontecimento em termos da sua importancia ou interesse como notícia, 
e b) os critérios contextuais que dizem respeito ao contexto de producão da notícia. Os valores-notícia de construcão são qualidades da sua construcão como notícia e funcionam como linhas-guia para a apresentacão do material, sugerindo o que deve ser realcado, o que deve ser omitido, o que deve ser prioritário na construcão do acontecimento como notícia (TRAQUINA, 2008, p. 78)

Tendo em vista essas definições, cabe destacar como os critérios substantivos são o norte deste trabalho, uma vez que estes se caracterizam como ferramentas que permitem uma análise do conteúdo de reportagens. Os critérios contextuais, como explicitado na passagem acima, se relacionam aos processos humanos e institucionais que se entrelaçam com o fazer jornalístico. Embora igualmente relevantes, são os substantivos que surgem como uma instância facilitadora no processo de análise e estudo dos motivos pelos quais um determinado assunto torna-se notícia.

A partir dessa escolha metodológica, é possível partir para um olhar atento quanto aos critérios substantivos definidos por Traquina. A morte, de acordo com o autor, se constitui como um dos critérios de maior importância para a comunidade interpretativa jornalística. A importância conferida a assassinatos, bombardeamentos e funerais, por exemplo, justificaria, de acordo com Traquina, uma prevalência de um certo negativismo do mundo do jornalismo.

Em seguida, Traquina destaca a notoriedade, ou seja, o critério em que a posição de importância do ator principal define o potencial noticioso de um fato. Uma decisão tomada pelo presidente da República se torna notícia devido ao peso do cargo em questão. Dessa forma, explicitando a maneira como o nome e o cargo de uma figura pública são indissociáveis de sua noticiabilidade.

A proximidade, por sua vez, diz respeito tanto ao aspecto geográfico, quanto ao aspecto cultural. Um acidente com mortos na cidade do Rio de Janeiro repercute regionalmente e, dependendo da gravidade, até nacionalmente. Mas dificilmente seria notícia em outro país. Traquina exemplifica a proximidade cultural a partir da explicação de Golding e Elliott, que apresentam como a cidade de Lagos, na Nigéria, se encontra mais culturalmente próxima de Londres, no continente europeu, do que de Accra, em Gana.

O critério da relevância se articula através do impacto de determinada notícia sobre o corpo social e seu respectivo contexto. Já a novidade diz respeito ao que há de novo, a partir do interesse da comunidade jornalística por fatos que justifiquem voltar a um assunto passado. Nesse cenário, o tempo é um critério que se articula em concomitância com a novidade. Para o autor, o critério do tempo justifica pautas que podem se resumir aos aniversários de eventos 
emblemáticos, tais como os dez anos dos atentados das torres gêmeas ou, em uma esfera nacional, os trinta anos da constituição de 1988.

Em âmbito distinto, a notabilidade é um critério que está ligado a tangibilidade de determinado assunto e, por consequência, à possibilidade de um fato se tornar palpável quando abordado por um viés jornalístico. Por exemplo: é difícil tangibilizar condições de trabalho adversas em uma fábrica, mas uma greve de seus funcionários facilmente se tornaria notícia. Já o critério do inesperado, se traduz como aquilo que traz surpresa, mega-acontecimentos e fatos que rompem com o tecido da normalidade como, por exemplo, os atentados de Nice, na França, em julho de 2016.

O conflito ou a controvérsia são classificações que dizem respeito à violência, seja essa física ou simbólica, tal como uma altercação física em um plenário. Por último, a infração se refere à violação de regras, estando intimamente ligada com o conceito de reportagens sobre crimes e, por consequência, à quebra da normatividade.

Novamente, cabe comentar como os critérios de Traquina surgem a partir de um estudo prévio por parte do autor de uma série de classificações propostas anteriormente por outros autores.

De acordo com Traquina, em sua definição de critérios de noticiabilidade, os circunstanciais dizem respeito à disponibilidade, ou seja, a facilidade de fazer a cobertura de determinado acontecimento; o equilíbrio, a relação entre determinado fato e a quantidade de matérias sobre esse mesmo acontecimento que já foram veiculadas recentemente; a visualidade, se há a existência de elementos visuais como fotos e filmes; a concorrência com outros veículos jornalísticos e o dia noticioso, ou seja, a concorrência de acontecimentos com outros acontecimentos.

Embora esses critérios também possam ser explorados no contexto do webjornalismo, cabe mencionar que a dinâmica da notícia em redes se configura de maneira totalmente distinta ao jornalismo clássico de redações. Como destacado anteriormente, a possibilidade de quantificar ações cotidianas devido à indissociação do público com o meio digital oferece uma série de possibilidades de formulação de pautas a partir do uso de dados. Além disso, a popularização das redes sociais também trouxe reflexões acadêmicas importantes sobre o que torna determinado conteúdo passível de se tornar notícia.

Apesar de não definir esta métrica como um arranjo de critérios de noticiabilidade propriamente ditos, Jenkins, Ford e Green (2013), ao observar a maneira como as redes sociais se constituem 
como um ambiente único para a disseminação de informação, propõem pressupostos para o caráter "espalhável" de uma notícia.

(a) esteja disponível quando e onde as audiências querem;

(b) seja portável;

(c) que possa ser facilmente reutilizada de diversas maneiras, como crossmedia, narrativas transmídia, que possam ser espalhadas;

(d) seja relevante a várias audiências;

(e) seja disponibilizado por meio de streaming

Outro aspecto importante introduzido pelas redes sociais é uma gradativa transformação da relação entre notícia e tempo. Embora o advento da televisão nos anos 1960 tenha trazido um grande avanço em termos de velocidade para veiculação de notícias, as redes sociais consolidaram a instantaneidade como aspecto central não apenas do fazer jornalístico, mas de toda uma dinâmica social da vida em sociedade:

A outra noção de tempo real se situa na dinâmica de produção de conteúdos em fluxo contínuo, particularmente no movimento de alimentação constante de notícias e sua fragmentação pela programação diária (às vezes nas 24 horas do dia), seja em rádio, televisão ou Internet. Esta segunda perspectiva induz o leitor a pensar que, se a disponibilização é contínua, a produção é contínua também, o que significaria mais pessoas produzindo mais conteúdos decorrentes de um envolvimento direto com mais situações, eventos ou temas - sequência indutiva que tende a não ser comprovada na averiguação de experiências práticas." (FRANCISCATO, 2004, p. 10-11)

Por fim, nota-se a maneira como os critérios de noticiabilidade de caráter substantivo mostramse imperativos como ferramentas para a análise de reportagens, uma vez que permitem um olhar sistematizado para com as inclinações discursivas de um texto. Também cabe perceber que o meio digital impõe a necessidade de acréscimo e revisões quanto a novos processos que têm se tornado intrínsecos à construção de matérias na web.

\section{Análise de reportagens do DeltaFolha}

A metodologia escolhida para seleção das reportagens teve como base o calendário das eleições municipais de 2020 do Tribunal Superior Eleitoral (TSE). Foram levantadas reportagens publicadas entre os dias 27 de setembro de 2020 (data da liberação para o início de veiculação de propagandas eleitorais) e 15 de novembro de 2020 (realização do $1^{\circ}$ turno). 
Ao todo, dezoito matérias se enquadraram nesses parâmetros. O foco determinado para as análises foi a política nacional. Dessa maneira, foram excluídas matérias relacionadas ao cenário internacional, como textos sobre as eleições presidenciais norte-americanas que ocorreram em novembro de 2020.

Em termos de utilização de dados para a construção de pautas, o veículo optou por fazer um uso extenso de informações oficiais do Tribunal Superior Eleitoral (TSE). Ao todo, foram treze reportagens que tiveram como mote para sua redação informações coletadas a partir do órgão.

O TSE conta com um amplo repositório de dados eleitorais disponíveis para consulta pública. As informações, que vão desde descrições sobre candidatos até prestações de contas partidárias e pesquisas eleitorais registradas, são atualizadas após cada eleição. Desta forma, o conteúdo disponibilizado pelo TSE se apresenta como campo fértil para elaboração de textos jornalísticos, sobretudo no que diz respeito ao jornalismo de dados. Com base nessas informações, o DeltaFolha apresentou diferentes recortes para construção de sua cobertura das eleições municipais.

O caráter racial foi o ponto de partida para a reportagem "Eleição tem recorde de mulheres candidatas e, pela $1^{\text {a }}$ vez, mais negros que brancos", publicada no dia 27 de setembro de 2020. A matéria utiliza dados sobre declaração de raça e gênero de candidatos registrados no TSE para costurar uma narrativa onde são explorados os motivos para o aumento das candidaturas de minorias. O texto aborda, com a fala de especialistas, a questão das cotas de distribuição de verbas de campanha, assim como a decisão do ministro do Supremo Tribunal Federal Ricardo Lewandowki de fixar cota financeira para negros.

Na matéria "Chegam a 42 mil os candidatos que mudaram declaração de cor para eleição deste ano" cabe observar, também, o uso de dados referentes às eleições de 2016. A utilização dessas informações, sob um olhar comparativo com o cenário descrito pelos dados de 2020, permitiu ao DeltaFolha construir reflexões que vão além apenas do cenário eleitoral atual.

Das dezoito matérias analisadas, seis utilizaram como gancho principal o registro de candidatos a partidos. Três reportagens demonstraram ênfase na figura do cargo de vereador, a posição política mais municipalizada presente no modelo político brasileiro. Porém, novamente, o recorte apresentado buscou descrever um cenário nacional, (foram os casos das reportagens "Em onda bolsonarista, Republicanos e PSL viram campeões em candidatos a vereador nas grandes cidades"; "Com até 44 anos de mandato, 'eternos vereadores' tentam reeleição" e "Vereadores migram para grandes partidos após veto das coligações nas eleições"). 
Nota-se, portanto, que apesar de a Folha de S. Paulo ser um jornal paulista, todas as matérias coletadas apresentaram enfoque nacional. Essa opção editorial está alinhada com o cenário virtual onde as matérias são veiculadas. Além disso, cabe ressaltar a maneira como a Folha já se apresentava como um jornal de inclinação nacional muito antes do advento da internet, como fica evidente pela página 2 de sua versão impressa que traz a frase "Um jornal a serviço do Brasil".

A partir das observações apresentadas aqui, podem ser delineadas algumas característicaschave da cobertura das eleições municipais de 2020 por parte DeltaFolha: há um grande enfoque sobre o cenário nacional; a fonte primária de dados é o Tribunal Superior Eleitoral e, por fim, há importante valorização da utilização de recursos visuais para representação de informações numéricas.

Tendo essas três conclusões iniciais como orientação, e utilizando os critérios de Nelson Traquina como base, foi possível montar a seguinte tabela, relacionando as classificações às matérias selecionadas:

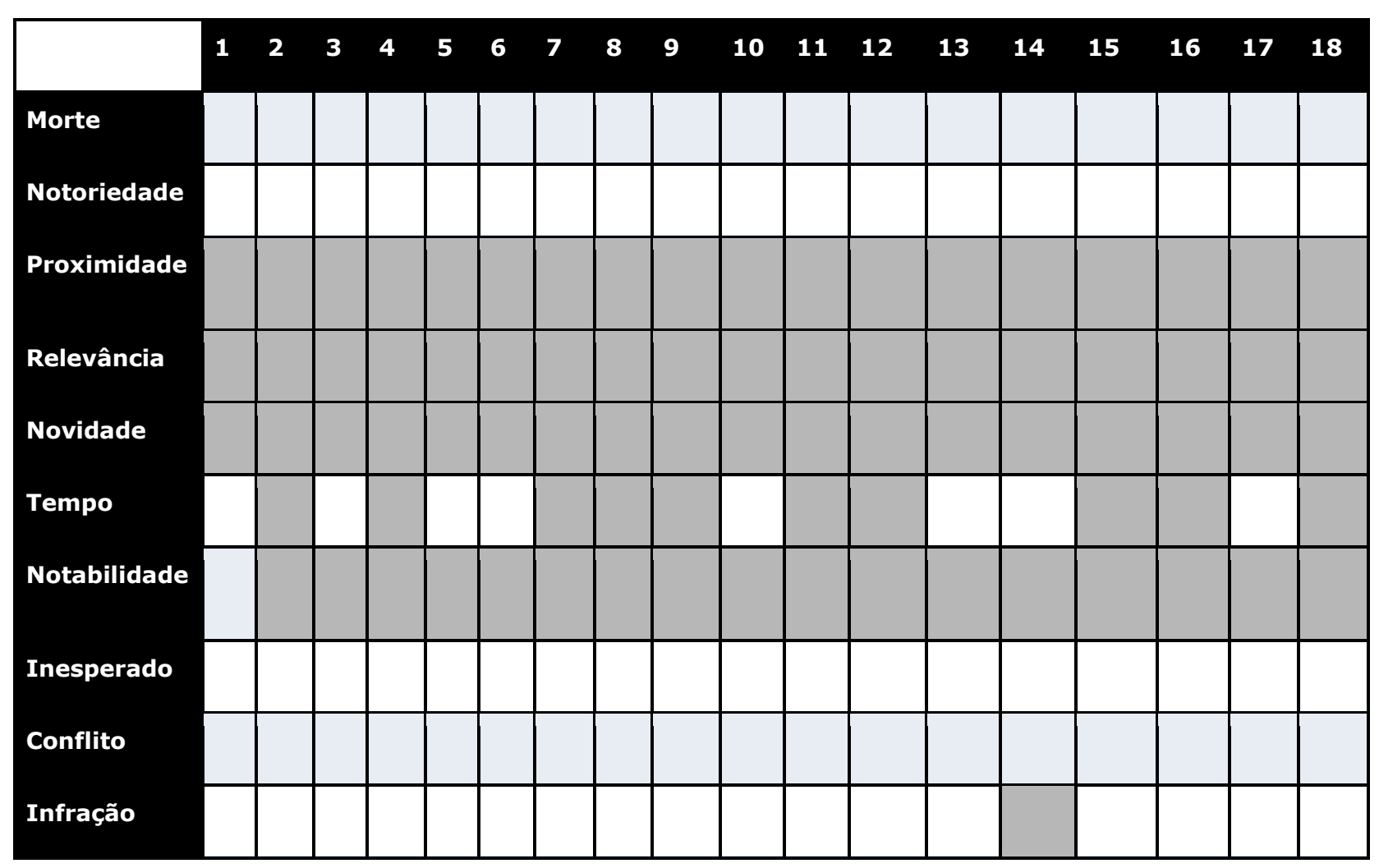


Constata-se a predominância dos critérios de proximidade, relevância, novidade e notabilidade.

A proximidade se constrói à medida que as eleições são um processo que diz respeito a todos os municípios do país (com a exceção do Distrito Federal). Dessa forma, estando em um campo de sentido muito próximo dos leitores ao redor do país. A relevância se articula em associação com este critério, uma vez que representa o impacto da corrida eleitoral frente aos eleitores (novamente, levando em consideração que as eleições municipais ocorrem em todo o país). A novidade, por sua vez, surge a partir da maneira como as informações tratadas pela Folha, a partir dos dados do TSE, são inéditas, ou seja, não surgem a partir do desdobramento de análises anteriormente realizadas. Já a notabilidade pode ser atribuída ao envolvimento de figuras políticas de destaque no conteúdo abordado pelas reportagens. O tempo foi um critério observado em reportagens que utilizavam dados de 2020 em comparação com outros anos, sobretudo com informações relacionadas às eleições de 2016. Por último, a infração só pôde ser percebida em uma reportagem ("Partidos descumprem regra de repasse de verba eleitoral para negros e mulheres").

Portanto, tendo em vista a forma como critérios de noticiabilidade são instrumentos para transformar a imensa gama de dados disponíveis no contexto da era da informação, em quantidades finitas de notícias a serem tratadas e veiculadas para o público, é possível dizer que o DeltaFolha opta por uma rota distante da cobertura habitual do jornalismo diário.

A maior quantidade de tempo necessário para produção de uma pauta, algo inerente ao jornalismo de dados, leva à opção por matérias de cunho analítico. Sendo assim, justifica-se a ausência de critérios como o conflito e a morte, classificações mais presentes na reportagem diária.

Informações quantitativas só passam a ser constituídas em pautas com potencial noticioso a partir de uma análise e tratamento por parte de jornalistas. Esse processo não é intuitivo e demanda um olhar profissional para com os dados tratados. Logo, torna-se importante, sob uma análise acadêmica, destacar a decisão da Folha de incluir em seus infográficos um rodapé com os dizeres "Dados do TSE, tabulados pela Folha". Ou seja, embora as informações apresentadas sejam de domínio público, seu potencial jornalístico foi conferido a partir do tratamento dessas informações e do recorte da pauta proposta pelo veículo.

Cabe salientar ainda como a demanda por mais tempo de produção torna pouco provável a veiculação de uma notícia particularmente quente por parte do DeltaFolha. Porém, as reportagens realizadas por essa sessão trazem consigo um caráter de urgência. Como discutido 
anteriormente, o jornalismo tem um papel de grande relevância para moldar a opinião pública e a cobertura política exerce papel importante para definição de cenários eleitorais.

Tendo em vista essas reflexões, a ausência de pautas predominantemente locais, apesar da cobertura ser centrada nas eleições municipais, suscita um outro tipo de proximidade com o leitor.

O repositório de dados eleitorais do TSE conta não apenas com dados de esfera nacional, mas também, informações referentes às 27 unidades da federação. Porém, em um contexto de eleições municipais, dados de cunho estadual se mostram insuficientes para a realização de análises pertinentes ao processo eleitoral.

No portal Estatísticas Eleitorais, também do TSE, é possível encontrar recortes demográficos mais específicos quanto ao eleitorado, candidaturas, comparecimentos e abstenções, dados processuais, resultados, prestação de contas e convocação de mesários. Essas informações podem ser filtradas por município ou até mesmo zona eleitoral. Entretanto, os dados são disponibilizados de maneira crua, não existindo uma ferramenta de pesquisa que torne possível a busca, por exemplo, do município brasileiro que teve maior número de abstenções. Para tanto, seria necessário tabular informações de todos os municípios para encontrar aquele com o maior índice. Sendo assim, tornam-se imperativos o tratamento e construção de recortes dos dados por parte de um jornalista.

De acordo com profissionais da Folha de S. Paulo que atuam no núcleo do DeltaFolha, traduzir análises estatisticamente sofisticadas de forma simples para o grande público é um desafio considerável. Essa observação, compartilhada por meio de entrevista, veio acompanhada de comentários sobre o processo de elaboração de pautas. Ainda segundo jornalistas do DeltaFolha, problemas na base de dados são dificuldades recorrentes.

Os profissionais destacaram o caso de uma reportagem que veio a se tornar manchete na Folha em 2018, em que foi necessário divulgar uma nota de "erramos". O erro ocorreu devido a um equívoco do TSE em explicar corretamente os pormenores sobre o perfil etário dos eleitores no Brasil.

Durante a organização interna para a cobertura das eleições municipais, meses antes do início do processo eleitoral, parte da equipe do DeltaFolha foi deslocada para dar início à preparação da base de dados necessárias para apurações. Essa decisão foi tomada com o objetivo de incrementar o banco de reportagens prontas para publicação nos dias próximos às votações, 
além de garantir tempo hábil para conclusão das pautas. Embora o TSE disponha de amplo repositório de dados com potencial informativo, nota-se que o tratamento e conversão dos mesmos em texto jornalístico de fácil compreensão são processos extensos e complexos, que demandam grande esforço de produção por parte de uma equipe de profissionais.

\section{Considerações finais}

A partir dos cenários descritos no presente trabalho, foi possível traçar conclusões importantes acerca da adoção do jornalismo de dados no contexto brasileiro. Primeiramente, a iniciativa da Folha de S. Paulo em adotar o uso de dados em suas coberturas, sobretudo com a criação do DeltaFolha para compilação dessas matérias, é uma decisão empresarial alinhada com grandes veículos de países como Estados Unidos e Inglaterra. Portanto, o DeltaFolha se apresenta como um representante brasileiro de uma tendência global de disseminação da modalidade no jornalismo.

O DeltaFolha se ancorou majoritariamente em informações do repositório de dados eleitorais do TSE. A partir de informações coletadas no banco de dados do órgão, o veículo realizou diferentes recortes narrativos para redação de reportagens. Esses recortes, por sua vez, trouxeram, novamente, um olhar sobre o macrocenário político nacional. Embora seja debatido que questões de espectro ideológico, assim como questionamentos sobre força partidária, sejam tópicos menos urgentes ao se tratar de eleições em cidades pequenas e médias, pôde-se perceber que a Folha se ateve a tais questões para traçar conclusões acerca de um contexto de Brasil.

Destaca-se, em última instância, a relevância do uso de dados na cobertura política. A partir da crescente disponibilidade de informações numéricas em decorrência de uma cultura mais conectada do que nunca, o jornalismo de dados surge como uma modalidade jornalística de grande importância para fins de investigação e construção de narrativas. Se faz necessário, portanto, sublinhar que o crescente protagonismo de algoritmos e dados numéricos no campo da comunicação, não se traduz em uma automatização do fazer jornalístico ou na diminuição da relevância profissional do jornalista. Pelo contrário. A realidade contemporânea, onde dados são cada vez mais acessíveis, demanda, mais do que nunca, um olhar crítico e analítico por parte de profissionais capacitados, de maneira a entregar informação precisa e de qualidade.

No contexto político, o jornalismo de dados contribui para o processo democrático e para a boa informação do eleitorado. 


\section{Referências bibliográficas}

BERRET, Charles; PHILLIPS, Cheryl. Teaching data and computational journalism. Nova Iorque: Rosemont Press, 2016.

DUTTA, Soumya; GANGOPADHYAY, Saswati. Digital Journalism: theorizing on present times. Media Watch, v. 10, n. 3, p. 713-722, set/2019.

FERES JÚNIOR, João.; SASSARA, Luna de Oliveira. O. O cão que nem sempre late: o Grupo Globo e a cobertura das eleições presidenciais de 2014 e 1998. Compolítica, Rio de Janeiro, v. 6, n. 1, p. 30-63, 2016.

FRANCISCATO, Carlos Eduardo. As novas configurações do jornalismo no suporte on-line. Revista de Economía Política de las Tecnologías de la Información y Comunicación, v. 6, n. 3, set- dez./2004.

GALTUNG, Johan; RUGE, Mari Holmboe. A estrutura do noticiário estrangeiro. A apresentação das crises do Congo, Cuba e Chipre em quatro jornais estrangeiros. In.: TRAQUINA, Nelson. Jornalismo (Org.), Questões, Teorias e "Estórias". Lisboa: Vega, 1993, p. 61-73.

GOLDING, Peter; ELLIOTT, Philip. Making the News. Londres: Longman, 1979

HOWARD, Alexander Benjamin. The art and science of datadriven journalism. Nova Iorque: Tow Center for Digital Journalism, Columbia University, 2014.

JENKINS, Henry; FORD, Sam; GREEN, Joshua. Spreadable Media: Creating Value and Meaning in a Networked Culture. Nova Iorque: NYU Press, 2013.

NUNES, Felipe.; MELO, Carlos Ranulfo. Impeachment, Political Crisis and Democracy in Brazil. Revista de Ciência Política. (Santiago), Santiago, v. 37, n. 2, 2017, pp. 281-304.

POWELL, Alison. Making and Measuring News: Data and Algorithms in Journalism.2016.

Disponível em: <http://eprints.Ise.ac.uk/76702/1/blogs.Ise.ac.uk-

Making\%20and\%20Measuring\%20News\%20Data\%20and\%20Algorithms\%20in\%20Journalism .pdf. > Acesso em: 15 ago. 2020.

SOUSA, Jorge Pedro (Org). Jornalismo, História, Teoria e Metodologia: Perspectivas lusobrasileiras. Porto: Universidade Fernando Pessoa, 2008.

SERRAT, Olivier. Storytelling. Washington: Asian Development Bank, 2008.

SILVA, Marcos Paulo da. Como os acontecimentos se tornam notícia: Uma revisão do conceito de noticiabilidade a partir das contribuições discursivas. Estudos em Jornalismo e Mídia, Florianópolis, v. 7, n. 1, p. 173-184, maio 2010.

SILVA, Gislene. Para pensar critérios de noticiabilidade. Estudos em Jornalismo e Mídia. Florianópolis, v. 2, n. 1, p. 95-107, jan./jun. 2005.

SEIXAS, Lia; ALVES, Jussara. Do que se trata noticiabilidade. Intexto, Porto Alegre, UFRGS, n. 38, p. 157-172, jan./abr. 2017. Disponível em <http://seer.ufrgs.br/index.php/intexto/article/view/61947> Acesso em 29 de agosto de 2020. 
TRAQUINA, N. Teorias do Jornalismo: porque as notícias são como são. Florianópolis: Insular, 2005.

. Teorias do Jornalismo. A tribo jornalística - uma comunidade interpretativa transnacional.Vol. 2 Florianópolis: Insular, 2008.

. As notícias. In: TRAQUINA, Nelson (Org.). Jornalismo: questões, teorias e "estórias". Lisboa: Vega, 1993.

\section{Reportagens analisadas:}

BRAGON, Ranier; GARCIA, Guilherme; FARIA, Flávia. Eleição tem recorde de mulheres candidatas e, pela $1^{a}$ vez, mais negros que brancos. 2020. Disponível em:

<https://www1.folha.uol.com.br/poder/2020/09/eleicao-tem-recorde-de-mulheres-candidatase-pela-1a-vez-mais-negros-que-brancos.shtml.> Acesso em: 27 set. 2020.

BRAGON, Ranier; GARCIA, Guilherme; FARIA, Flávia. Chegam a 42 mil os candidatos que mudaram declaração de cor para eleição deste ano. 2020. Disponível em:

<https://www1.folha.uol.com.br/poder/2020/09/chegam-a-42-mil-os-candidatos-quemudaram-declaracao-de-cor-para-eleicao-deste-ano.shtml.> Acesso em: 27 set. 2020. PITOMBO, João Pedro; GARCIA, Guilherme. Metade das chapas para prefeituras é formada apenas por candidatos brancos. 2020. Disponível em: <https://www1.folha.uol.com.br/poder/2020/09/metade-das-chapas-para-prefeituras-eformada-apenas-por-candidatos-brancos.shtml.> Acesso em: 28 set. 2020.

LEE, Bruno; GARCIA, Guilherme. Número de militares e policiais candidatos a prefeito é o maior em 16 anos. 2020. Disponível em:

<https://www1.folha.uol.com.br/poder/2020/09/numero-de-militares-e-policiais-candidatos-aprefeito-e-o-maior-em-16-anos.shtml.> Acesso em: 29 set. 2020.

BRAGON, Ranier; GARCIA, Guilherme. PT isolado e avanço do bolsonarismo marcam candidaturas nas maiores cidades do país. 2020. Disponível em:

<https://www1.folha.uol.com.br/poder/2020/10/pt-isolado-e-avanco-do-bolsonarismomarcam-candidaturas-nas-maiores-cidades-do-pais.shtml.> Acesso em: 1 out. 2020. BRAGON, Ranier; GARCIA, Guilherme. PSDB e MDB conseguem maior arco de apoio na eleição das grandes cidades. Disponível em:

<https://www1.folha.uol.com.br/poder/2020/10/psdb-e-mdb-conseguem-maior-arco-deapoio-na-eleicao-das-grandes-cidades.shtml. > Acesso em: 4 out. 2020.

BRAGON, Ranier; GARCIA, N Guilherme. Em onda bolsonarista, Republicanos e PSL viram campeões em candidatos a vereador nas grandes cidades. 2020. Disponível em: <https://www1.folha.uol.com.br/poder/2020/10/em-onda-bolsonarista-republicanos-e-pslviram-campeoes-em-candidatos-a-vereador-nas-grandes-cidades.shtml.> Acesso em: 7 out. 2020. 
VERONEZI, Luciano; FARIA, Flávia; GARCIA, Guilherme. Eleição tem 108 candidatos únicos a prefeito, 11 mil milionários e uma série de peculiaridades; veja algumas. 2020. Disponível em: <https://www1.folha.uol.com.br/poder/2020/10/eleicao-tem-108-candidatosunicos-a-prefeito-11-mil-milionarios-e-uma-serie-de-peculiaridades-veja-algumas.shtml.> Acesso em: 9 out. 2020.

BRAGON, Ranier; GARCIA, Guilherme. Homem branco é o candidato padrão a prefeito nas 95 maiores cidades do país. 2020. Disponível em:

<https://www1.folha.uol.com.br/poder/2020/10/homem-branco-e-o-candidato-padrao-aprefeito-nas-95-maiores-cidades-do-pais.shtml.> Acesso em: 13 out. 2020.

GARCIA, Guilherme; YUKARI, Diana; TAKAHASHI, Fábio. Indicado por Bolsonaro ao Supremo, Kassio foge do padrão dos demais ministros da corte. 2020. Disponível em: <https://www1.folha.uol.com.br/poder/2020/10/indicado-por-bolsonaro-ao-supremo-kassiofoge-do-padrao-dos-demais-ministros-da-corte.shtml.> Acesso em: 14 out. 2020.

PITOMBO, João Pedro; GARCIA, Guilherme. Vereadores migram para grandes partidos após veto das coligações nas eleições. Disponível em:

<https://www1.folha.uol.com.br/poder/2020/10/vereadores-migram-para-grandes-partidosapos-veto-das-coligacoes-partidarias.shtml.> Acesso em: 16 out. 2020.

PITOMBO, João Pedro; GARCIA, Guilherme. Com até 44 anos de mandato, 'eternos vereadores' tentam reeleição. Disponível em:

<https://www1.folha.uol.com.br/poder/2020/10/com-ate-44-anos-de-mandato-eternosvereadores-tentam-reeleicao.shtml.> Acesso em: 18 out. 2020.

BRAGON, Ranier; GARCIA, Guilherme; YUKARI, Diana. Menos de 1\% dos candidatos concentram $\mathbf{8 0} \%$ dos fundos públicos de campanha. 2020. Disponível em:

<https://www1.folha.uol.com.br/poder/2020/10/menos-de-1-dos-candidatos-concentram-80dos-fundos-publicos-de-campanha.shtml.> Acesso em: 25 out. 2020.

BRAGON, Ranier; GARCIA, Guilherme. Partidos descumprem regra de repasse de verba eleitoral para negros e mulheres. Disponível em:

<https://www1.folha.uol.com.br/poder/2020/11/partidos-descumprem-regra-de-repasse-deverba-de-campanha-para-negros-e-mulheres.shtml.> Acesso em: 1 nov. 2020. PITOMBO, João Pedro; GARCIA, Guilherme. Hegemonia de MDB e PSDB nos municípios será colocada em xeque nas urnas. 2020. Disponível em:

<https://www1.folha.uol.com.br/poder/2020/11/hegemonia-de-mdb-e-psdb-nos-municipiossera-colocada-em-xeque-nas-urnas.shtml.> Acesso em: 8 nov. 2020.

PITOMBO, João Pedro; GARCIA, Guilherme. País tem 75 municípios que há duas décadas vivem uma espécie de dinastia partidária. 2020. Disponível em:

<https://www1.folha.uol.com.br/poder/2020/11/pais-tem-75-municipios-que-ha-duasdecadas-vivem-uma-especie-de-dinastia-partidaria.shtml.> Acesso em: 10 nov. 2020. 
Folha de S. Paulo. Folha lança página Minha Cidade na Eleição com indicadores de todos os municípios do país. 2020. Disponível em:

<https://www1.folha.uol.com.br/poder/2020/11/folha-lanca-pagina-minha-cidade-na-eleicaocom-indicadores-de-todos-os-municipios-do-pais.shtml.> Acesso em: 10 nov. 2020.

MARIANI, Daniel; TAKAHASHI, Fábio; YUKARI, Diana. Eleição nas capitais dificilmente terá onda de direita como nas disputas de 2016 e 2018. 2020. Disponível em:

<https://www1.folha.uol.com.br/poder/2020/11/eleicao-nas-capitais-dificilmente-tera-ondade-direita-como-nas-ultimas-eleicoes.shtml.> Acesso em: 12 nov. 2020. 